Int. J. Gynaecol. Obstet., 1981, 19: 313-317

(c) International Federation of Gynaecology \& Obstetrics

\title{
VAGINAL EVISCERATION
}

\author{
YEW CHEONG CHOO and S. MARTIN LINDENAUER
}

Division of Gynecologic Oncology, Department of Obstetrics and Gynecology, University of Michigan Medical School, Ann Arbor, MI, USA

(Received December 1st, 1980)

(Accepted December 18th, 1980)

\section{Abstract}

Choo YC, Lindenauer SM (Division of Gynecologic Oncology, Department of Obstetrics and Gynecology, University of Michigan Medical School, Ann Arbor, MI, USA). Vaginal evisceration.

Int J Gynaecol Obstet 19: 313-317, 1981

$A$ patient with vaginal evisceration due to prior radiation treatment of cervical carcinoma is presented, together with a review of reported cases. The salient features, predisposing causes and management of this unusual problem are discussed.

Key words: Vaginal evisceration Cervical carcinoma Irradiation

\section{Introduction}

Despite its inherent potential to descensus and the occurrence of senescent atrophy, the vagina is an extremely resilient organ even in the elderly. It is frequently subjected to obstetrical, surgical and sexual trauma, yet disruption and evisceration rarely occur. McGregor [1] first reported a vaginal evisceration in 1907. Friedel and Kaiser [2] in 1975 collected 36 cases but they included cases of forniceal rupture without evisceration and omitted those in which there was only omental prolapse. A recent patient with vaginal evisceration prompted a review of the literature, disclosing 44 similar cases and forms the basis of this report.

\section{Case report}

R.J. is a 50-year-old nulliparous white female who was admitted to the University of Michigan Hospital on March 5, 1979 with a chief complaint of a protruding mass in the vagina. She related that following a bout of coughing, she suddenly experienced local discomfort in the vagina associated with wetness in both thighs, and felt a mass protruding into the vagina. Physical examination revealed the patient in no acute distress. A loop of small intestine was seen prolapsing through a vault defect into the vagina (Fig. 1). The cervix and uterus were absent. The bowel appeared viable but congested with areas of local edema. It was reduceable and straining did not cause further prolapse. There were multiple loops of intestine adherent to the prolapsed segment and to the vaginal defect. The vagina measured $4 \mathrm{~cm}$ in depth, with an obvious rectovaginal and vesico-vaginal fistula present. There was no evidence of recurrent carcinoma. Her past history revealed that she had a stage II B squamous cell carcinoma of the cervix treated elsewhere in 1975 with radiation. Prior to that she had undergone appendectomy, cholecystectomy and tubal ligation. Her cervical lesion was described as involving the entire cervix and extending to both lateral fornices and rectovaginal septum. Radiation treatment was begun on April 15, 1975 with external cobalt therapy through an anterior and posterior portal $(15 \times 16 \mathrm{~cm})$, delivering a mid plane dose of 2172 rads in 12 treat- 


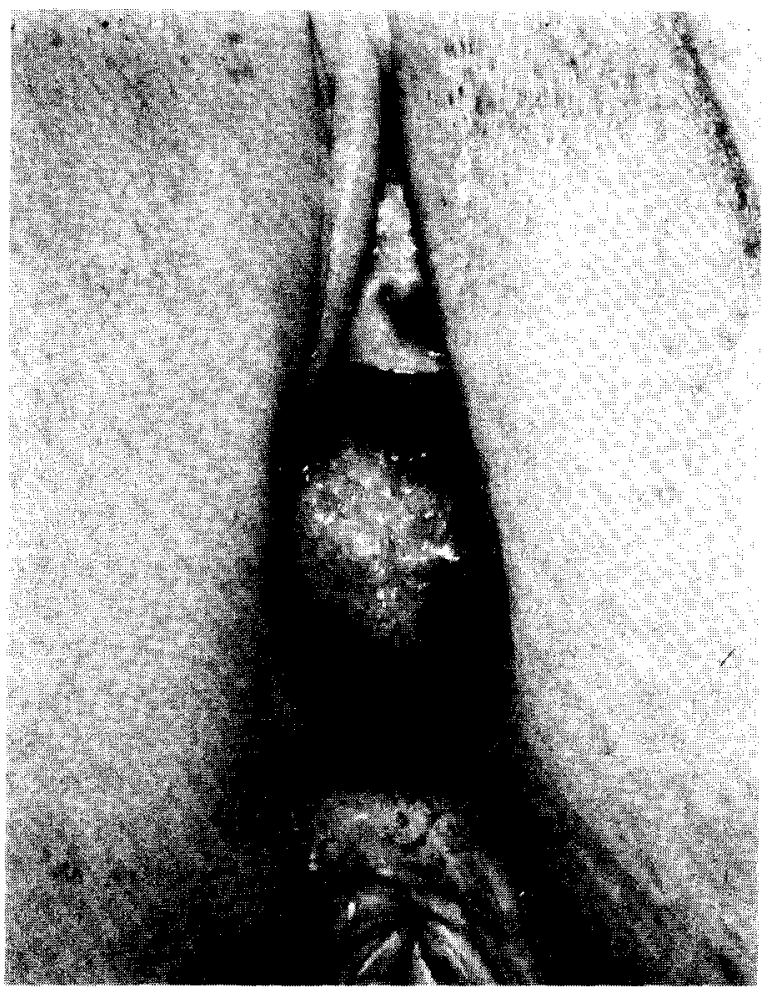

Fig. 1. Photograph demonstrating evisceration of a loop of small intestine into the vagina. Local edema and congestion is evident.

ments over 16 days (180 rads daily). Following this a radium implant was performed consisting of $15-10-10 \mathrm{mg}$ radium in the tanden and $20 \mathrm{mg}$ radium in each Manchester ovoid for $12 \mathrm{~h}$. A second implant followed 9 days later containing the same amount of radium for $48 \mathrm{~h}$. She was then continued on external therapy through a right and left pelvic field, $(13 \times 6 \mathrm{~cm})$, delivering a dose of 2100 rads in 12 treatments over 15 days.

One year later, she developed a large recto-vaginal fistula and had a sigmoid colostomy. Soon thereafter, a vesico-vaginal fistula developed and she underwent a cutaneous jejuno-ureterostomy. Multiple biopsies at that time revealed no recurrent neoplasm.

Vaginal repair and colpocleisis was attempted with reconstruction of a new perineum by approximation of the levator ani and with overlapping flaps of bulbo- carvenosus and labia majora but this was unsuccessful due to wound breakdown. Further attempt at perineal reconstruction was to employ gracilis myocutaneous flap but this was declined by the patient. Meanwhile, the prolapsed Loop of intestine became well-contained within the vagina by multi-intestinal loop adhesions which formed a shelf above. Her subsequent follow-up revealed no additional difficulties.

\section{Comments}

This patient's vaginal evisceration was a result of radiation-induced destruction of pelvic supporting tissues. Her treatment posed a considerable dilemma. An abdominal approach would seem formidable and hazardous. On the other hand, a simple vaginal closure would fail from poor healing and possible wound breakdown as a result of previous intense local radiation and local contamination. At present, the patient is contended with wearing a protective perineal pad only.

\section{Discussion}

Vaginal evisceration is predominantly a phenomenon of the aged. Among the 45 cases described in the literature, in which age of the patient is noted, more than half occurred after the age of 50 . The youngest patient was age 20 [3], and the eldest, 84 [4].

\section{Etiology}

Previous hysterectomy and pelvic relaxation are the most important contributing factors to vaginal evisceration. Twenty-four patients had had a prior hysterectomy - 16 vaginal (five with simultaneous vaginal colporrhaphy), and eight abdominal. Ten patients had a history of a prior vaginal colporrhaphy as the only operation. This included. three who had a Manchester procedure. Interestingly, following hysterectomy 
and/or vaginal colporrhaphy, 16 patients devcloped an enterocele which ruptured, leading to evisceration. The interval from operation to evisceration varied from as little as 3.5 months [5] to as long as 25 years [6].

Radiation for invasive carcinoma of cervix was the preceding event recorded in only one patient [7]. Three additional patients received radiation in the form of a radium implant for carcinoma in situ of the vagina [8], fibroid of the uterus [9], and artificial menopause [10].

Coital injury as a direct cause of evisceration was documented in five patients. Two occurred in post-menopausal patients $[8,11]$, the remainder in younger individuals. Two were attributable to sexual injury occurring within [6] months following abdominal hysterectomy $[12,13]$, and one was attributed to a forceful rape in a 20 year old [3].

Obstetrical trauma leading to vaginal evisceration was reported in three patients: two following version and extraction $[8,14]$ and one following forceps application before the cervix was fully dilated [8].

Other forms of trauma, such as douching [5], enema expulsion [9], speculum insertion [2] and a fall $[1,15,16]$ have been described infrequently.

The precipitating event in many of the non-traumatic cases were often trivial such as defecation [7,8,17-19] squatting [20], and coughing $[21,22]$. In 10 patients $[4,6,10,23-29]$, however, the occurrence appeared to be spontaneous, related probably to an exceedingly thin and stretched-out vaginal apex yielding to a transient increase in intra-abdominal pressure.

\section{Symptoms and signs}

When intestine prolapses through a disrupted enterocele, posterior fornix or vaginal vault following hysterectomy, the presentation is usually sudden, with vaginal discomfort. The patient may report fluid track- ing down the medial aspect of both thighs following which, it becomes clear that intestine has prolapsed through the vagina. There may be a variable degree of bleeding from the rupture site; two patients, in fact, presented in shock $[2,11]$. The finding of intestine in the vagina is a frightful experience. The patient, in a state of panic, invariably summons whatever help possible. A few, particularly the old and the debilitated, may present with the late sequlae of irreduceability and strangulation from neglect. Nine patients presented with intestinal obstruction $[4,8,10,17,21,23,27,30]$, six with strangulation $[10,21,23,27,30]$, and one with mesenteric thrombosis [8].

The small intestine was the commonest prolapsed viscera, reported in 33 patients. Eight patients had omental prolapse only $[5,15,16,28,31-33]$; one patient had prolapse of small intestine with omentum [14]; two had extrusion of small intestine and salpinx [3,21], and one had prolapse of pelvic colon [26].

The length of prolapsed bowel varied, with the longest recorded length being $1.5 \mathrm{~m}$. This catastrophe occurred in a patient while straining on the toilet [19].

\section{Management}

Vaginal evisceration, as in abdominal evisceration, is generally considered a surgical emergency. Procrastination leads to peritonitis, ileus and intestinal obstruction, further compromising the status of these elderly patients. A history of instrumentation or insertion of a foreign body should be sought. The prolapsed bowel is inspected and its reduceability and viability ascertained. After cleansing with warm saline, it is wrapped in moist sterile pads.

The definitive surgical treatment may be undertaken by either a vaginal, abdominal, or combined vaginal-abdominal approach. The vaginal approach is satisfactory in uncomplicated cases. After thorough irrigation, the bowel is reduced with the patient in 
Trendelenberg position, and the defect closed, by reapproximation of the peritoneum and the vaginal vault. The placement of a drain seems advisable. An enterocele, if present, can be repaired simultaneously or postponed to a later date. At times, the vaginal defect may require enlargement in order to facilitate reduction. When sexual function is not a consideration in an elderly patient, a colpocleisis may be performed, or a new perinuem constructed, by approximating the vagina, levator ani and vulva.

An abdominal approach is undertaken when exploration is required because of intestinal obstruction or a similar intraabdominal problem. Trans-abdominal repair of the vaginal defect can be achieved by this approach which can be strengthened further by placement of an omental falp or obliteration of the cul de sac by concentric purse string sutures as described by Moschowitz.

A combined abdominal-vaginal approach may be required to achieve reduction of an incarcerated loop of intestine. Intestinal resection may be necessary and closure of the vaginal defect can be accomplished from a vaginal, transabdominal or combined approach.

Patients undergoing abdominal exploration run a high risk of abdominal evisceration perhaps due to the poor nutritional status of these patients, and a transverse abdominal incision or a vertical incision with wire closure is recommended. In this series of 45 patients, 21 had vaginal closure, 12 had repair via an abdominal approach, and 12 had a combined abdominal-vaginal repair. Bowel resection was carried out in seven patients $[8,19,23,27,29,30]$.

\section{Complications}

Complications reported in this group of patients included paralytic ileus in five, postoperative fever in three, and abdominal wound evisceration in four patients $[2,10$, 12,21]. Four deaths occurred (9\%) [8,27,
30]: two as a result of bowel strangulation; one each from pulmonary embolus and cerebral vascular accident.

\section{Summary}

Forty-five reported cases of vaginal evisceration are reviewed. Excluding direct trauma, vaginal evisceration is a potential threat in any patient with an enterocele or a weakened vaginal vault following hysterectomy. It is therefore imperative that prophylatic plication of utero-sacral ligaments be undertaken at the time of vaginal hysterectomy, and an enterocele be recognized and repaired. Post-menopausal patients with an enlarging enterocele should undergo surgical repair to avoid vaginal evisceration.

\section{References}

1 McGregor AN: Rupture of the vaginal wall with protrusion of small intestines in a woman 63 years of age. Replacement, suture, recovery. J Obstet Gynecol $\mathrm{Br}$ Emp 11:252, 1907.

2 Friedel W, Kaiser IH: Vaginal evisceration. Obstet Gynecol 45: 315, 1975.

3 Haney AF: Vaginal evisceration after forcible coitus with intraabdominal ejaculation. J Reprod Med 21: 254, 1978.

4 Annenbery AD: Ruptured enterocele. Obstet Gynecol 24: 893, 1964.

5 McNellis D, Torkelson L, McElin TW: Late post-operative vaginal vault disruption. Am J Obstet Gynecol 94: $543,1966$.

6 Fox WP: Vaginal evisceration. Obstet Gynecol 50: 223, 1977.

7 Habeck EA, Peters LM: Evisceration of bowel through the vagina following irradiation for cervical carcinoma. Report of first known case. Wis Med J 67: 374, 1968.

8 Roff BB: Vaginal evisceration. Am J Obstet Gynecol 107: 369, 1970.

9 Kayser FW, Heaney NS, Dahleen HC: Spontaneous evisceration through vaginal enterocele. Am J Obstet Gynecol 61: 1393, 1951.

10 Galloway RK, Edmond P, Hamilton T: Vault rupture with bowel prolapse after Manchester repair. J Obstet Gynecol Br Commonw 76: 1035, 1969.

11 Lask S: Perforation of the posterior fornix and pouch of Douglas during coitus. Br Med J 1: 786, 1948.

12 Powell JL: Vaginal evisceration following vaginal hysterectomy. Am J Obstet Gynecol 115: 276, 1973. 
13 MoGinn RC, Grannum PAT, Reichenbach AE: Vaginal evisceration following total abdominal hysterectomy. Conn Med 41: 410, 1977.

14 Baldwin GL: Discussion of Rolf [8]. Am J Obstet Gynecol 107: 375, 1970.

15 Weisse HA, Watson M, Steffan CT: Traumatic rupture of the apex of vagina, twenty months following abdominal hysterectorny. Am J Obstel Gynecol 76: 1207, 1958.

16 Richards BL: Vaginal evisceration. Am J Obstet Gynecol 123: 915,1975 .

17 Brose P: Zwei Kranke nach Extirpation des Uterus wegen prolaps. Gynaekologe 33: 916, 1909.

18 Fox PC: Eventration of the intestine through the vagina following vaginal hysterectomy. Ill Med J 96: 321, 1949.

19 Hobbs FS: Spontaneous evisceration through vagina. Can Med Assoc J 66: 68, 1952.

20 Hoffman, RL: Discussion of Kinzel. Am J Obstet Gynecol 81: 1173, 1961.

21 Dunn CE: Disruption of vaginal wound with evisceration 18 months following vaginal hysterectomy. J Mich Med Soc 49: 925, 1950.

22 Outerbridge GW: Intestinal evisceration through the vaginal vault subsequent to vaginal hysterectomy. Am J Obstet Gynecol 65: 439, 1953.

23 Mctregor JK, Priore R: Ruptured vaginal enterocele. Obstet Gynecol 20: 78, 1972.

24 Fox PF, Kwslczyk AS: Ruptured enterocele. An J Obstet Gynecol 111: 592, 1971.

25 Symmonds RE, Pratt JH, Ellis FH, Jr: Ruptured enterocele. Am J Obstet Gynecol 74: 1150, 1957.
26 Thompson W: A case of intestinal obstruction associated with a ruptured enterocele. J Obstet Gynecol Br Emp 55: $664,1948$.

27 Heys RF: Ileal prolapse through ruptured vagina: Complications of Manchester operation. Br Med J 2: 223, 1963.

28 Shaul DL: Spontaneous rupture of enterocele following vaginal hysterectomy, Am J Obstet Gynecol 85: 281, 1963.

29 Hunter RE, Jahadi MR, Chandler JP: Spontaneous rupture of enterocele. Obstet Gynecol 36: 835, 1970.

30 Daley D, Callum EN: A case of intestinal obstruction associated with complete procidentia. J Obstet Gynecol Br. Emp 53: 68, 1946.

31 Johnson FL: Editorial comment. Discussion on Hunter [29] Am J Obstet Gynecol 85: 282, 1963.

32 Foster W: Editorial Comment. Am J Obstet Gynecol 107: 375, 1970.

33 Kennedy JW, Campbell AD: Vaginal Hysterectomy, p 181. F.A. Davis Co., Philadelphia, 1942.

\section{Address for reprints:}

Dr. Y.C. Choo

Department of Obstetrics and Gynecology

Queen Mary Hospital

University of Hong Kong

Hong Kong 